\title{
Dyskinesia, cardiac arrhythmia and partial seizure associated with paliperidone overdose: a case report
}

\author{
Antonio Villa, ${ }^{1}$ Giulia Gallotta, ${ }^{1}$ Alessia Malaguti, ${ }^{2}$ Vilma Galimberti, ${ }^{3}$ Raffaella Leva ${ }^{1}$ \\ ${ }^{1}$ Emergency Department; ${ }^{2}$ Department of Psychiatry; ${ }^{3}$ Department of Neurology, Hospital of Desio-Vimercate (MI), Italy
}

\begin{abstract}
Paliperidone is a new atypical antipsychotic agent. There are few literature reports of paliperidone overdoses and we report a case of these. A 32-year-old man was admitted to Emergency Department for occurrence of opisthotonus, muscular spasms and rigidity. Twenty hours before, he had an ingestion of $168 \mathrm{mg}$ of paliperidone. He had hypotension and tachycardia. The dystonic reaction completely resolved within a few minutes after diazepam. Nine hours after admission, he sudden showed a right hemisoma partial seizure. The peculiar interest of our case is that three different and rare symptoms occurred in successive times after overdose. Some symptoms occurred after several hours following overdose. Oral paliperidone is available as an osmotic release delivery system that results in a gradual rise in plasma concentrations. According to this limited experience in which delayed onset of toxicity has been observed, it may be prudent to recommend prolonged observation after overdose of paliperidone.
\end{abstract}

\section{Introduction}

Paliperidone (or 9-hydroxyrisperidone) is a new atypical antipsychotic agent. It is the primary active metabolite of risperidone. Although it is approved for the treatment of schizophrenia and schizoaffective disorders, off-label uses include management of psychosis and bipolar disorder. ${ }^{1,2}$ Paliperidone is available as an extended-release oral tablet.

The safety of paliperidone was evaluated in sixweek clinical trials performed prior to Food and Drug

Correspondence: Antonio Villa, via Fiuggi 56, 20159 Milano, Italy.

Tel.: +39.338.6562521

E-mail: antonio.villa@aovimercate.org

Key words: Paliperidone; overdose; dyskinesia; arrhythmia; partial seizure.

Contributions: $\mathrm{AV}$, case acquisition, analysis and interpretation, manuscript writing; GG, clinical investigation, manuscript writing; AM, VG, RL, clinical investigation.

Conflict of interest: the authors declare no potential conflict of interest.

Received for publication: 22 November 2014.

Revision received: 13 January 2015.

Accepted for publication: 17 January 2015.

This work is licensed under a Creative Commons Attribution NonCommercial 3.0 License (CC BY-NC 3.0).

(C) Copyright A. Villa et al., 2015

Licensee PAGEPress, Italy

Italian Journal of Medicine 2015; 9:373-376

doi:10.4081/itjm.2015.563
Administration (FDA) approval. In these placebo-controlled double-blind trials, the most common adverse reactions were extrapyramidal symptoms (3-10\%), tachycardia (9-22\%), hyperkinesia (3-11\%), hypertonia (1-6\%), and drowsiness (4-13\%). ${ }^{3,4}$ Other observed side effects were cardiac disorders (various cardiac rhythm disturbances, prolonged QTc interval, orthostatic hypotension), gastrointestinal disorders, anxiety, sleep disorder, headache. ${ }^{4,5}$ There are few literature reports of paliperidone overdoses ${ }^{6-11}$ and its safety in overdose has not been established.

We report a case of paliperidone overdose in a patient with psychosis showing three concomitant different clinical pictures.

\section{Case Report}

A 32-year-old man with a history of psychosis was admitted to our Emergency Department (ED) for occurrence of opisthotonus, muscular spasms and rigidity, and tongue protrusion.

Twenty hours before, he had an intentional ingestion of $168 \mathrm{mg}$ of extended-release paliperidone. He had a background history of an untreated psychosis; the patient reported no history of seizures or arrhythmias. He denied any medication use and no other concomitant drug ingestion. He recently consulted a psychiatrist and paliperidone was prescribed, but he was not compliant with this prescription.

At ED, he had hypotension (blood pressure: 100/60 $\mathrm{mmHg}$ ) and tachycardia (pulse rate: $170 \mathrm{bpm}$ ); his consciousness was clear with a full score of Glasgow coma scale. His head was rigid and rotated and tongue clonus was observed.

A 12-lead electrocardiogram (ECG) revealed a 
narrow complex tachycardia (Figure 1), at $154 \mathrm{bpm}$, with possible presence of first degree atrioventricular block (PQ 0.22") or atrial flutter with 2:1 conduction. QT interval was prolonged (QTc $545 \mathrm{~ms}$ ).

The dystonic reaction completely resolved within a few minutes after diazepam intravenously.

His blood biochemistry revealed the following (laboratory reference range): glucose, $119(65-100) \mathrm{mg} / \mathrm{dL}$; creatinine, $0.73(0.5-1.2) \mathrm{mg} / \mathrm{dL}$; potassium, 4.0 (3.54.5) $\mathrm{mMol} / \mathrm{L}$; sodium, 139 (135-145) $\mathrm{mMol} / \mathrm{L}$; creatine kinase, 92 (38-174) U/L; serum ethanol absent. The arterial blood gas analysis was normal.

The contacted Anti-poisoning Center suggested only prolonged observation and cardiac monitoring.

After $3 \mathrm{~h}$ from ED arrival, blood pressure was $115 / 70 \mathrm{mmHg}$ and heart rate was $70 \mathrm{bpm}$. A 12-lead ECG showed sinus rhythm with normalization of PQ and QT intervals.

Nine hours after ED admission, he sudden showed a right hemisoma partial seizure. Another diazepam administration resolved the crisis. The cerebral computed tomography scan was normal.

After $24 \mathrm{~h}$ of intensive observation the patient was admitted to Psychiatric ward.

During the time of hospitalization he was asymptomatic for neurological disorders, remained with sinus mild tachycardia for other 10 days. On day 22 he was discharged in stable conditions and his vital signs were normal.

\section{Discussion}

Paliperidone is the major active metabolite of risperidone (9-hydroxirisperidone). The mechanism of action, similar to other atypical antipsychotic agents, is central dopamine type 2 and serotonine type $\alpha 2$ receptor antagonism. Additionally, paliperidone acts as an antagonist at $\alpha 1$ and $\alpha 2$ adrenergic and histamine receptors. ${ }^{10}$ Antagonism of the serotonin $\alpha 2$ and dopamine 2 receptors is responsible for the therapeutic effects on the negative and positive symptoms of schizophrenia, respectively. ${ }^{9}$ However, antagonism of the dopamine 2 and serotonin $\alpha 2$ receptors can also lead to extrapyramidal symptoms, restlessness, agitation and akathisia. Antagonism of the histamine 1 receptors results in sedation, whereas antagonism of $\alpha 1$ receptor results in orthostasis and reflex tachycardia.

Acute dystonic reactions related to paliperidone were described in 2 case reports; ${ }^{10,11}$ there are also few cases in premarketing trials reported by manufacturer with the highest ingestion that resulted in extrapyramidal symptoms and gait unsteadiness. ${ }^{1}$

Neuroleptic-induced acute dystonia is common with neuroleptic treatment, and occurs in more than $50 \%$ of the high-risk group. ${ }^{12}$

In several studies, tachycardia was one of the most common adverse events observed. ${ }^{4,13}$

Boom and coll. ${ }^{14}$ examined the pharmacodynamic effects of various dosing regimens of paliperidone. After administration of a single dose of $15 \mathrm{mg}$ of paliperidone, the mean pulse rate increased by 22 beats/min, and the maximal mean pulse rate occurred nearly $36 \mathrm{~h}$ post-ingestion.

Atypical antipsychotic have an established risk of causing cardiac rhythm disturbances, including tachycardia, arrhythmias, and QT interval prolongation. Risperidone may precipitate cardiovascular adverse

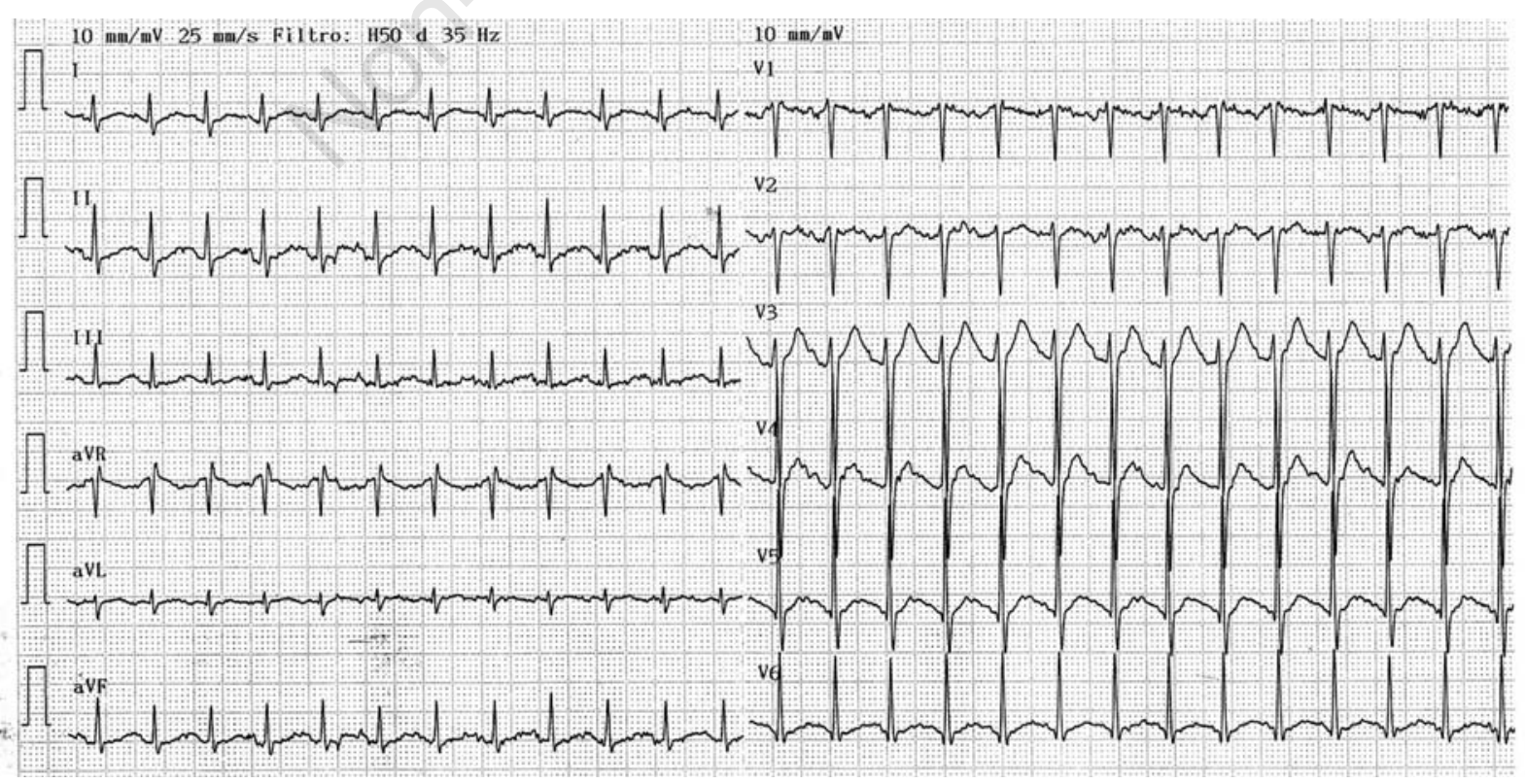

Figure 1. Electrocardiogram upon the arrival at Emergency Department. 
events, such as atrioventricular block, myocardial infarction, hypertension, premature atrial contractions, ventricular tachycardia, tachycardia, bradyarrhythmias, and electrocardiogram abnormalities. The frequency of tachyarrhythmias with risperidone therapy was $1-7 \%$ in clinical trials. ${ }^{2}$ In premarketing studies, paliperidone was similarly linked to several cardiac problems, including bradyarrhythmias $(0.1-1 \%)$, tachyarrhythmias (12-14\%), and Q-T interval prolongation (3-5\%)., ${ }^{3,4,13}$

Atypical antipsychotics have a potential to lower seizure thereshold. ${ }^{2}$

According to the FDA's Adverse Event Reporting System (AERS) several reports of seizures have been linked to risperidone therapy. ${ }^{2}$ Instead, only two cases of a seizure related to paliperidone therapy was reported;2,15 during three premarketing clinical trials, seizures occurred in $0.22 \%$ of subjects treated with paliperidone and $0.25 \%$ of subjects treated with placebo. $3,4,13$

The peculiar interest of our case is that three different and rare (or less) symptoms occurred in successive times after paliperidone overdose.

The clinical experience with paliperidone overdose is limited. To our knowledge there are few cases of paliperidone intoxication published since its approval. ${ }^{6-11}$ In the FDA pre-marketing database two mortality cases are reported under paliperidone treatment. ${ }^{7}$ Since both of those patients were also under some other medications the relationships between causes of death and the use of paliperidone remained unclear.

In Table 1 we summarized the most important signs and symptoms observed in patients with paliperidone overdose and the time course from occurrence ${ }^{6-11}$

The first case of paliperidone overdose was described by Chang and coll. ${ }^{6}$ in 2010. A 26-year-old male with schizophrenia was admitted to acute psychiatric ward for severe symptoms of restlessness and anxiety. Three days prior to admission he started to self-medicate with triple prescribed doses of paliperidone (a total of $81 \mathrm{mg}$ in 3 days). In ED he had hypertension and tachycardia.
In the same year, other two cases have been described $^{7,8}$ with an overdose on a total of $243 \mathrm{mg}$ and $756 \mathrm{mg}$ of paliperidone, respectively. A patient was admitted to ED with restlessness, agitation, mild confusion, disorganized behavior, hypertension, and tachycardia. ${ }^{7}$ Seventy-two hours of monitoring ended without any sequelae. The other patient did not suffer any major adverse clinical events, adverse laboratory parameters, or long lasting sequelae. ${ }^{8}$ In our case there was no agitation or anxiety, but muscular spasms and dyskinetic crisis were present.

In the case described by Lapid and coll., ${ }^{10} \mathrm{a}$ young male admitted to the intensive care unit after a multidrug ingestion with $42 \mathrm{mg}$ of paliperidone, bupropion, sertraline and lorazepam, acute dystonia developed $48 \mathrm{~h}$ following the overdose.

Acute extrapyramidal symptoms are described in paliperidone overdose; bupropion and sertraline have also been associated with dystonic reactions. Our patient did not take any other medication and thus the dystonic crisis should be due to paliperidone.

In the case described by Levine and coll., ${ }^{9}$ after ingestion of $180 \mathrm{mg}$ of paliperidone adverse cardiac effect (a narrow complex tachycardia) developed $26.5 \mathrm{~h}$ post-ingestion.

Finally, Liang and coll. ${ }^{11}$ described an acute renal failure in a young patient that ingested $48 \mathrm{mg}$ of paliperidone. In our patient renal function was normal.

In all described cases and in our patient some symptoms occurred after several hours following overdose (until $48 \mathrm{~h}$ ).

Oral paliperidone is available as an osmotic release delivery system that results in a gradual rise in plasma paliperidone concentrations, reaching a peak plasma concentration approximately $24 \mathrm{~h}$ following a single dose, while the elimination half-life is $23 \mathrm{~h} .{ }^{1}$ The osmotic release oral delivery system of paliperidone explains how an acute adverse effect might occur over $24 \mathrm{~h}$ after the overdose. ${ }^{10}$

The drug's delivery matrix likely contributed to the delayed onset of symptoms and extended duration of symptoms.

Table 1. Signs and symptoms and their time course from occurrence, in patients with paliperidone overdose (as reported in literature).

\begin{tabular}{lcccccc}
\hline Author (mg of paliperidone) & Arrhythmias & Agitation & Dyskinesia & Coma confusion & Seizures & Others \\
\hline Chang $^{6}(81 \mathrm{mg})$ & $>48 \mathrm{~h}$ & $>48 \mathrm{~h}$ & - & - & - & Hypertension \\
\hline $\mathrm{Bez}^{7}(243 \mathrm{mg})$ & $6 \mathrm{~h}$ & $6 \mathrm{~h}$ & $6 \mathrm{~h}$ & $6 \mathrm{~h}$ & - & Hypertension \\
\hline $\operatorname{Gill}^{8}(756 \mathrm{mg})$ & - & - & - & - & - & None \\
\hline $\mathrm{Levine}^{9}(180 \mathrm{mg})$ & $26.5 \mathrm{~h}$ & - & - & - & - & - \\
\hline Lapid $^{10}(42 \mathrm{mg})$ & - & - & $48 \mathrm{~h}$ & $48 \mathrm{~h}$ & - & - \\
\hline Liang $^{11}(48 \mathrm{mg})$ & - & - & - & - & - & Acute renal failure \\
\hline Present case $(168 \mathrm{mg})$ & $20 \mathrm{~h}$ & - & $20 \mathrm{~h}$ & - & $29 \mathrm{~h}$ & -
\end{tabular}


Similar to Levine's case, ${ }^{9}$ our patient never received any form of gastro-intestinal decontamination, specifically he did not receive any activated charcoal or laxative. It is possible that if he had received this therapy, decreased absorption would have occurred.

\section{Conclusions}

Vigilance with newer antipsychotic agents is needed especially in the setting of drug overdose. Paliperidone intoxication must be managed by appropriate supportive measures because there is no known specific antidote. Management includes administration of activated charcoal and laxative, maintaining airway and ensuring adequate ventilation and oxygenation, and continuous cardiovascular monitoring. ${ }^{7,10}$

According to this limited experience in which delayed onset of toxicity has been observed, it may be prudent to recommend prolonged observation after overdose of paliperidone.

\section{References}

1. Invega (Paliperidone) extended-release tablets [product insert]. Titusville, NJ: Ortho-McNeil-Janssen Pharmaceutical Inc.; 2007.

2. Schneider RA, Lizer MH. Apparent seizure and atrial fibrillation associated with paliperidone. Am J Health Syst Pharm 2008;15:2122-5.

3. Davidson M, Emsley R, Kramer M, et al. Efficacy, safety, and early response of paliperidone extended-release tablets (paliperidone ER): results of a 6-week, randomized, placebo-controlled study. Schizophr Res 2007; 93:117-30.

4. Kane J, Canas F, Kramer M, et al. Treatment of schizophrenia with paliperidone extended-release tablets. A 6- week placebo-controlled trial. Schizophr Res 2007;90: 147-61.

5. Gentile S. Adverse effects associated with second-generation antipsychotic long-acting injection treatment: a comprehensive systematic review. Pharmacotherapy 2013;33:1087-106.

6. Chang JPC, Huang CC, Su KP. Paliperidone overdose in a patient with schizophrenia. Progr Neuropsycopharmacol Biol Psychiatry 2010;34:418.

7. Bez Y, Donmezdil S, Sir A. Suicide attempt with paliperidone overdose: a case report. Bull Clin Psychopharmacol 2010;20:155-7.

8. Gill JS, Pillai SK, Koh OH, Jambunathan S. Non-fatal paliperidone overdose: a case report. Turk Psikiyatri Derg 2010;21:331-4.

9. Levine M, Lovecchio F, Tafoya P, Graham R. Paliperidone overdose with delayed onset of toxicity. Ann Emerg Med 2011;58:80-2.

10. Lapid MI, Cunningham JL, Hugo Z, Kung S. Acute dystonia associated with paliperidone overdose. Psychosomatics 2011;52:291-4.

11. Liang CS, Bai YM, Liou YJ, Chou YH. Acute renal failure after paliperidone overdose: a case report. J Clin Psycopharmacol 2012;32:128.

12. Casey DE. Narcoleptics-induced acute dystonia. In: Widiger TA, American Psychiatric Association Task Force on DSM-IV, eds. DSM-IV Sourcebook. Vol I. Washington, DC: American Psychiatric Publishing, Inc.; 1994.

13. Kramer M, Simpson G, Maciulis V, et al. Paliperidone extended-release tablets for prevention of symptom recurrence in patients with schizophrenia: a randomized, double-bind, placebo-controlled study. J Clin Psychopharmacol 2007;27:6-14.

14. Boom S, Talluri K, Janssens L, et al. Single and multiple dose pharmacokinetics and dose proportionally of the psychotropic agent paliperidone extended release. J Clin Pharmacol 2009;49:1318-27.

15. Liang CS, Yang FW, Chiang KT. Paliperidone-associated seizure after discontinuation of sodium valproate: a case report. J Clin Psychopharmacol 2011;31:246-7. 